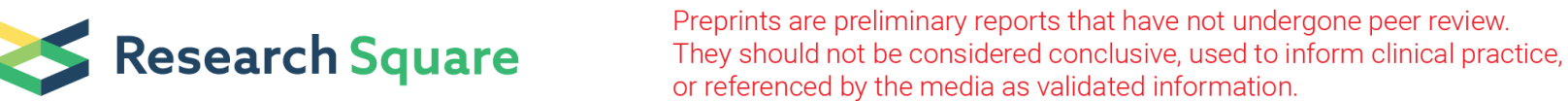

\section{Associations of blood essential and toxic metal(loid)s with both disease severity and mortality in patients with COVID-19: a retrospective study}

\section{Hao-Long Zeng}

Tongji Hospital of Tongji Medical College of Huazhong University of Science and Technology

\section{Qing Yang}

wuhan polytechnic university

\section{Peihong Yuan}

Tongji Hospital of Tongji Medical College of Huazhong University of Science and Technology

\section{Xu Wang}

Tongji Hospital of Tongji Medical College of Huazhong University of Science and Technology

Liming Cheng ( $\square$ chengliming2015@163.com )

Tongji Hospital of Tongji Medical College of Huazhong University of Science and Technology https://orcid.org/0000-0003-3042-371X

\section{Research}

Keywords: COVID-19, metals, metalloids, whole blood, severity, mortality

Posted Date: August 11th, 2020

DOI: https://doi.org/10.21203/rs.3.rs-54691/v1

License: (c) (i) This work is licensed under a Creative Commons Attribution 4.0 International License.

Read Full License 


\section{Abstract}

Background The variations and dynamics of blood essential and toxic metal(loid)s in patients with COVID-19 still remains unclear.

Methods A retrospective study was performed in a cohort of confirmed COVID-19 patients for their whole blood levels of essential and/or toxic metal(loid)s including magnesium, calcium, chromium, manganese, iron, copper, zinc, arsenic, cadmium, mercury, thallium and lead according to the disease severity and outcome.

Results Compared to the non-severe COVID-19 patients, Whole blood calcium, chromium and copper were higher in the severe patients, while magnesium, manganese, iron, zinc, arsenic, thallium and lead were lower. These differences were further found to be consistently existed across the clinical course since the disease onset by longitudinal analysis. Moreover, among the severe patients, chromium and cadmium were higher in the deceased group compared to the recovered group, while arsenic were found to be lower. Whole blood iron, arsenic, and age and sex were determined to be independently factors associated with the disease severity, while chromium, cadmium and the co-morbidity of cardiovascular disease were determined to be independently factors associated with the mortality.

Conclusions These results suggest variations of whole blood metal(loid)s as associated factors correlated with the disease severity and mortality for COVID-19.

\section{Background}

Since the first known cases were reported in December, 2019, the coronavirus disease 2019 (COVID-19) that caused by severe acute respiratory syndrome coronavirus 2 (SARS-CoV-2) has spread worldwide and has been classified by the World Health Organization (WHO) as a global pandemic [1]. The clinical manifestation of COVID-19 might be asymptomatic or moderate to severe with coughing, fever, and shortness of breath [2]. Up to 10-20\% of the patients develop a severe disease characterized by interstitial pneumonia and the rapid development of acute respiratory distress syndrome or septic shock $[3,4]$. Patients with any comorbidities yielded poorer clinical outcomes than those without [5]. The most prevalent comorbidity was hypertension (22.9\%), followed by diabetes $(11.5 \%)$, and cardiovascular disease $(9.7 \%)[6]$.

Public health practices including social distancing, handwashing and vaccinations help reduce the spread and impact of infections. Nevertheless, the global burden of infection is high, and the need for identifying the factors to reduce the risk of SARS-CoV- 2 infection that could be adopted by a large population at a low cost with minimal risk is a medical priority at this time of crisis [7].

Given that the importance that nutrition plays in immune function is well established, abnormities of micronutrient status is supposed to be associated with increased infection risk of COVID-19 [8]. Inadequate intake and status of micronutrients are widespread, leading to a decrease in resistance to 
infections and as a consequence an increase in disease burden [9]. Poor nutrient status is associated with inflammation and oxidative stress, which in turn can impact the immune system. A wealth of mechanistic and clinical data show that essential micronutrients, including calcium, chromium, copper, magnesium, manganese, iron and zinc play important and complementary roles in supporting the immune system and prevent infection [10].

Beyond that, environmental pollutes are believed to contribute to the increased prevalence of chronic diseases including diabetes and cardiovascular disease [11-13], and seems to be associated with immunodeficiency observed in the contemporary pandemic, such as COVID-19 [14]. It has been reported that HIV-infected patients and people at high risk of HIV have significantly higher body burden of heavy metals $[15,16]$. However, no previous studies have examined the body burden of environmental pollutants including heavy metals among COVID-19 patients.

In the present study, we are aimed to perform a retrospective analysis of the essential minerals and heavy metals in whole blood of patients with COVID-19, and further investigate their associations with the severity of the disease (non-severe or severe) and outcomes (recovered or deceased), respectively.

\section{Materials And Methods}

\subsection{Patients}

The retrospective cohort study was performed in a designated hospital for COVID-19 treatment in Tongji Hospital of Huazhong University of Science and Technology, Wuhan, Hubei Province. A total of 306 patients with confirmed COVID-19 admitted to the hospital were enrolled into the study. The diagnosis and clinical classification of COVID-19 were carried out in accordance with the Guidelines of the Diagnosis and Treatment of New Coronavirus Pneumonia published by the National Health Commission of China [17]. The clinical classification were briefly described as below: (1) Mild cases: Mild symptoms without sign of pneumonia on imaging. (2) Moderate cases: Fever and respiratory symptoms with radiological findings of pneumonia. (3) Severe cases: Respiratory distress ( $\geqq 30$ breaths/ min), or Oxygen saturation $\leq 93 \%$ at rest, or Arterial partial pressure of oxygen $(\mathrm{PaO} 2) /$ fraction of inspired oxygen (FiO2) $\leqq 300 \mathrm{mmHg}$, or Lesion progression within $24-48$ hours $>50 \%$ by chest imaging. (4) Critical cases: Respiratory failure and requiring mechanical ventilation, or Shock, or With other organ failure that requires ICU care. In the present study, The mild and moderate cases were collectively referred to as non-severe cases, while the severe and critical cases were collectively referred to as severe cases. All the patients had determined outcomes, and the characteristics were summarized in Table $\mathbf{S 1 .}$

This study was approved by the Ethics Committee of Tongji Hospital, Tongji Medical College, Huazhong University of Science and Technology in Wuhan, China (No.:TJ-IRB20200201). All the procedures involving human samples conformed to the principles outlined in the Declaration of Helsinki. All the analysis were performed on existing samples collected during standard diagnostic tests, posing no extra burden to patients. 


\subsection{Sample preparation and instrumental analysis}

At least $2 \mathrm{~mL}$ of blood was collected in $6 \mathrm{~mL}$ special polyethylene terephthalate vacuum vials, for trace elements, containing $10 \mathrm{mg}$ potassium ethylene diamine tetracetic acid (BD Vacutainer product). Standard stainless steel needles were used (Precision glide, Becton Dickinson). All measurements were carried out in the Department of laboratory medicine, Tongji hospital of Tongji Medical College in Huazhong University of Science \& Technology, with a quadruple inductively coupled plasma mass spectrometer (ICP-MS) equipped with a concentric glass nebulizer and a cyclonic spray chamber ((7700x ICP-MS system, Agilent Technologies, USA). Analyses were performed in standard mode and dynamic collision cell mode.

For Cadmium (Cd), Mercury ( $\mathrm{Hg})$, Thallium $(\mathrm{Tl})$ and Lead $(\mathrm{Pb})$, the assays were run in standard mode. For Magnesium (Mg), Calcium (Ca), Copper (Cu), Zinc (Zn), Iron (Fe), Chromium (Cr), Manganese (Mn), Arsenic (As), assays were run in dynamic collision cell mode (collision cell gas: helium, $>99.995 \%)$. The preparations of calibration standards, the detailed ICP-MS operating conditions and the limit of qualification (LoQ) were described in our previous report [18]. Blood samples (200 ul) were diluted 1:20 $(\mathrm{v} / \mathrm{v})$ with an aqueous solution containing $0.1 \%(\mathrm{v} / \mathrm{v})$ Triton X-100 (Sigma-Aldrich, France) and $0.1 \%$ nitric acid ( $\geq 69 \%$, Merck, Germany). The samples were vortexed in a table-top vortexer for $30 \mathrm{~s}$. The diluted samples were then quantified by ICP-MS.

\subsection{Quality Control and Quality Assurance}

The Department of laboratory medicine of Tongji hospital is a IS015189 accredited laboratory, and also certified by College of American Pathologist (CAP). Internal quality assessment (IQA) was carried out during analysis by using the traceable Seronorm whole blood materials L-2 (ref.:210205) and L-3 (ref.:210305) (https://www.sero.no/products/seronorm-trace-elements-whole-blood/). And another low concentration home-made quality controls L-1 were prepared by diluting the Seronorm L-2 five times. Internal quality controls were tested following every twenty specimens to ensure quality throughout screening. The Z-score was calculated, and the values within the +2 to -2 range were satisfactory and indicated analytical trueness. External quality assessment (EQA) was carried out by participation in the College of American Pathologists (CAP) proficiency program (https://www.cap.org/laboratoryimprovement/proficiency- testing ) and the NCCL (National Center for Clinical Laboratories) external quality assessment (EQA) scheme (https://www.nccl.org.cn/ptCn).

\subsection{Data analysis}

Descriptive statistics were performed with continuous variables estimated as median and interquartile range (IQR), and categorical variables summarized as frequencies and proportions. The reference range of each trace elements in Wuhan residents were described as we recently reported [18]. Considering the distributions of the elements tested by the Kolmogorov-Smirov test, were mostly not normal, The nonparametric tests were used in our data analysis. The Mann-Whitney $U$ test was used to compare the results between different disease severities and different outcomes, respectively. The Spearman 
correlation test and its statistical significance were used to assess the correlation between the different elements. The trace elements were tested for their discriminative power in determining the predictive criteria for disease progression and fatal outcome by calculating the area under the receiver operating characteristic (ROC) curve. Sensitivity and specificity were calculated according to ROC curves for each parameter. Multivariate logistic regression were performed to adjust the effect from whole blood elements, age and sex, and co-morbidities of hypertension, diabetes and cardiovascular disease. For data analysis, individual results below the limit of qualification (LoQ) were replaced by the (LoQ/2) value. All analyses were performed using SPSS version 22.0 (SPSS, Chicago, USA) and $p<0.05$ was considered statistically significant.

\section{Results}

The present study included a total of 306 hospitalized patients with confirmed COVID-19. The median age was 63.0 years old (IQR: 53.3-70.0). Among them, 158 (51.6\%) were female and all were of Wuhan residents. All the patients were classified on admission according to severity of the disease, as severe cases $(\mathrm{N}=104(34.0 \%))$ or non-severe cases $(\mathrm{N}=202(66.0 \%))$ (Table 1). All the patients had determined outcomes, of which all the non-severe cases $(202,100.0 \%)$ and $89(85.6 \%)$ severe cases recovered, the remained 15 (14.4\%) severe cases deceased (Table 1). Altogether, a total of 291 (95.1\%) patients recovered and 15 (4.9\%) deceased. The median duration of hospital stay was 30 days (IQR: 19-41). The median length from disease onset to admission was 21 days (IQR: 11-34). The frequently seen symptoms at hospital admission were fever, cough, feebleness, chest tightness, shortness of breath and diarrhea. Of the 306 patients, $238(77.8 \%)$ had at least one underlying conditions, including hypertension $(118,38.6 \%)$, diabetes $(59,19.3 \%)$, cardiovascular disease $(42,13.7 \%)$, malignancy $(14,4.6 \%)$, cerebrovascular disease $(19,6.2 \%)$ (Table 1$)$.

For all these patients, the median of the whole blood metal(loid)s were $39.13 \mathrm{mg} / \mathrm{L}$ (magnesium), $64.54 \mathrm{mg} / \mathrm{L}$ (calcium), $0.85 \mu \mathrm{g} / \mathrm{L}$ (chromium), $12.05 \mu \mathrm{g} / \mathrm{L}$ (manganese), $419.87 \mathrm{mg} / \mathrm{L}$ (iron), $865.02 \mu \mathrm{g} / \mathrm{L}$ (copper), $6.44 \mathrm{mg} / \mathrm{L}$ (zinc), $1.43 \mu \mathrm{g} / \mathrm{L}$ (arsenic), $0.70 \mu \mathrm{g} / \mathrm{L}$ (cadmium), $1.56 \mu \mathrm{g} / \mathrm{L}$ (mercury), $<0.05 \mu \mathrm{g} / \mathrm{L}$ (thallium) and $11.56 \mu \mathrm{g} / \mathrm{L}$ (lead), respectively, as listed in Table 2 . Among them, most were within the reference range, except that the median of whole blood chromium were above the upper limit.

Between severe and non-severe group, except for cadmium and mercury, the other ten metal(loid)s including magnesium, calcium, chromium, manganese, iron, copper, zinc, arsenic and thallium displayed significant differences (Table 2, Fig. S1). Among them, whole blood calcium, chromium and copper were higher in the severe patients, while magnesium, manganese, iron, zinc, arsenic, thallium and lead were lower $(p<0.05)$. For the severe patients, chromium and cadmium were found to be higher in the deceased group compared to the recovered group, while Arsenic were found to be lower $(p<0.05)$ (Table 3, Fig. S2). The longitudinal changes of these metal(loid)s were further analyzed according to the disease severity. As shown in Fig. 1, the higher levels of whole blood calcium, chromium and copper and lower levels of magnesium, manganese, iron, zinc, arsenic, thallium and lead in the severe group than the non-severe group seemed to be consistently existed across the clinical course since the disease onset. 
The correlation matrix were further established to check the inter-metal(loid) correlations, as summarized in Table S1. The most positive correlations were found among the essential metals magnesium, manganese, iron and zinc, with the highest correlation coefficient (CC) of 0.64 for iron-zinc, followed by 0.55 for iron-magnesium, and 0.51 for iron-manganese. Among the heavy metals, arsenic-thallium showed the highest coefficient of 0.43 . The most negative correlations were found as iron-calcium (CC $=$ $-0.59)$, zinc-calcium $(C C=-0.52)$ and iron-chromium $(C C=-0.35)$.

For the ten metalloids and the two metalloids that displayed a statistically significant difference at univariate analysis between different disease severities and outcomes, respectively, we calculated the optimum diagnostic cut-off points of severe versus non-severe group and recovered versus deceased group, respectively, by using the ROC curve method. The specified cut-off points and the sensitivity, specificity and the area underneath the ROC curve belonging to those cut-off points are shown in Table S2.

For the disease severity, two indicators had AUC $>0.70$, including iron and arsenic (Table S2), therefore were used by applying multivariate logistic regression to the predetermined cut-off values. Finally, age, sex, and whole blood iron and arsenic were determined to be independently predictive of severe illness ( $p$ $<0.05)$. The risk for a fatal clinical outcome increased 3.667, 1.962, 2.406 and 3.136 times in the presence of age $\nabla 65$ years old, male, iron $\nabla 376.67 \mathrm{mg} / \mathrm{L}$, arsenic $\otimes 1.24 \mu \mathrm{g} / \mathrm{L}$, respectively (Table 4 ). These indicators collectively could discriminate $76.5 \%$ of the patients that might progress to severe illness (data not shown).

For the disease outcome, three indicators had $A U C>0.70$, including chromium, arsenic and cadmium (Table S2), and used for the multivariate logistic regression. Finally, whole blood chromium, cadmium and the comorbidity of cardiovascular diseases were determined to be independently predictive of fatal outcome $(p<0.05)$. The risk for a severe illness increased $9.595,12.734$ and 6.91 times in the presence of chromium $\geq 1.32 \mu \mathrm{g} / \mathrm{L}$, cadmium $\geq 0.68 \mu \mathrm{g} / \mathrm{L}$ and cardiovascular diseases, respectively (Table 5 ). These indicators collectively could discriminate $87.5 \%$ of the patients that might progress to severe illness (data not shown).

\section{Discussion}

To our knowledge, this is the first study focusing on the associations of the whole blood metalloids with the severity and outcome of COVID-19. We performed a retrospective study of 306 patients with COVID-19 for their whole blood levels of essential minerals including magnesium, calcium, chromium, manganese, iron, copper, zinc, and toxic metal(loid)s including arsenic, cadmium, mercury, thallium and lead according to the disease severity (severe or non-severe) and outcomes (recovered or deceased), respectively. Our data revealed the whole blood magnesium, cadmium, chromium, manganese, iron, copper, zinc, arsenic and thallium displayed significant differences between severe and non-severe group $(p<0.05)$, and the whole blood chromium, cadmium and arsenic displayed differences between the deceased group and recovered group $(p<0.05)$. These data suggested the whole blood levels of essential 
minerals and toxic metal(loid)s may be associated with the disease progression and outcome, and could be potential risk factors correlated with the severe illness and mortality of COVID-19.

For essential minerals, as the world awaits an effective vaccine, nutrition may play an important and safe role in helping mitigate patient morbidity and mortality. Optimal nutritional status of relevant nutrients is important for a well-functioning immune system during the COVID-19 crisis [8, 9]. Among the many essential nutrients, magnesium is the second most abundant intracellular cation after potassium, and involved in > 600 enzymatic reactions in the body, including those contributing to the exaggerated immune and inflammatory responses exhibited by COVID-19 patients [19]. Our data suggested the significant lower levels of magnesium in severe patients with COVID-19 than in the non-severe patients, which is consistent with the hypothesis by Stefano lotti that a low Mg status might foment the transition from mild to severe clinical manifestations of the COVID-19 [20]. Several aspects of the COVID-19 mimic the metabolic events shown to occur during latent subclinical magnesium deficiency, such as a drop of T cells, increased plasma concentration of inflammatory cytokines, and endothelial dysfunction $[19,20]$. Constant monitoring of magnesium status was thought as an possible strategy to influence disease contraction and progression [19].

Calcium was reported as a key role in viral fusion for many enveloped viruses such as SARS-CoV, MERSCoV and Ebola virus [21]. Low levels of serum total and ionized calcium were reported in COVID-19 patients [22]. Hypocalcemia had already shown to be common in patients with SARS and in patients with Ebola virus disease, and may occur also in COVID-19 [21]. However, our data suggested a mild increase of whole blood total calcium ( 63.55 to $68.20 \mathrm{mg} / \mathrm{L}$ ) in severe COVID-19 patients than non-severe cases. We suspected that these amount of increased calcium may be from the protein-binding forms or due to the variations of the blood cells, which need to be confirmed in future studies.

Chromium is an essential micronutrient involved in carbohydrate, lipid and protein metabolism primarily by increasing insulin efficiency $[23,24]$. Previous study has confirmed the drastic increase of urinary chromium in patients with diabetes [23]. Chromium is also a naturally occurring heavy metal found commonly in the environment, which could affect various components of the immune system and may result in immunostimulation or immunosuppression [25]. Higher levels of chromium in severe and deceased patients with COVID-19, suggested by our study, may be related to the comorbidity of diabetes and the immune dysfunction in COVID-19.

Transition metals such as manganese, iron, copper, and zinc are essential for all forms of life, as $30 \%$ of enzymes require a metal cofactor [26]. Clinical deficiency of manganese, iron or zinc in the host increases the incidence of infectious disease and mortality [27], which is consistent, to a certain extent, with our findings that the whole blood manganese, iron or zinc decreased in the severe COVID-19 patients than non-severe patients. Among then, manganese has been reported of playing a important role in innate immune activation and host anti-viral defense, as it released from organelles into the cytosol upon virus infection and facilitates the activation of CGAS and STING signaling [27]. For iron, systemic dysregulation resulted from COVID-19 hyperinflammation has been recently reviewed [28]. Serum iron level was 
reported as a potential predictor of COVID-19 severity and mortality [29]. Decreased serum iron level could predict the transition of COVID-19 from mild to severe and critical illness [30, 29], which was in agreement with our findings. Zinc is one of the micronutrients that could be consumed to reduce the intensity of SARS-CoV-2 infection and perhaps lessen the respiratory tract infection through the antiviral actions [7]. Zinc deficiency can contribute to defective cell-mediated immunity and to increased susceptibility to various infections, including pneumonia [31]. Several lines of evidence suggest a link between zinc and COVID-19, including the observation that chloroquine, a drug being repurposed for COVID-19, is a known zinc ionophore [32]. SARS-CoV and SARS-CoV-2 use the host zinc metalloenzyme, ACE2, as an entry point to cells [33]. Consistent with these overall findings, our data suggested the lower level of whole blood zinc, and also the transition metal manganese and iron, were associated with the severe illness of COVID19. Our finding that these essential minerals including manganese, iron, zinc and magnesium positively correlated with each other with the highest coefficients further implied a possible synergistic effect of the metals on the disease.

In contrast to the transition metals above, copper showed a different changes, as it increased in the severe patients compared with the non-severe cases. This difference may be associated with the two sides of copper, as it is an essential micronutrient for both pathogens and the animal hosts they infect, and also be toxic in cells due to its redox properties and ability to disrupt active sites of metalloproteins [34]. Animal host can thwart pathogen growth by limiting their copper nutrients, similar to the welldocumented nutritional immunity effects for starving microbes of essential zinc, manganese and iron micronutrients [34]. Meanwhile, a common hallmark of infection irrespective of the agent (viral, bacterial, fungal) is a marked and progressive rise in serum copper, including the lung infections [35-37]. In addition, the increased serum copper to zinc ratio has been reported to be associated with the inflammation conditions [38], as similar with the findings in the present study.

Besides the micronutrients discussed above, environmental pollutants, including the heavy metals or metalloids, are believed to be associated with the viral epidemic/pandemic events and prevalence [14]. In the present study, the heavy metals in whole blood were investigated, among which, cadmium was found to be higher in the deceased cases. Cadmium has cumulative toxicity to many organs due to its long biological half-life. It was reported that exposure to cadmium and lead could cause adverse effect on human health on the respiratory system with lung function impairment [39].

However, the arsenic, lead and thallium showed lower levels in whole blood of the severe cases than the non-severe cases, and the arsenic also showed a lower level in deceased cases than the recovered cases. These results were unexpected, as exposure to heavy metals was commonly reported to induces respiratory dysfunction and positively correlated with the occurrence of respiratory diseases [40]. Considering that the heavy metals in whole blood were found to be at relatively low levels in our study, which were all within the baseline range or mildly lower than the lower limit in all the patients with COVID19 , we suspected that the decrease of the circulatory heavy metals in severe patients with COVID-19 may be attributed to the abnormalities of peripheral blood system [41]. The positive correlations among arsenic, thallium and lead suggested by our results implied a similar mechanism existed for these 
elements. The mechanisms of lower levels of whole blood arsenic, thallium and lead in severe or deceased COVID-19 patients need to be verified and clarified in the future studies.

There are some limitations should be noted. This study was based on only 306 severe or non-severe patients with COVID-19 in Wuhan of China. Specifically for the severe group, deceased cases accounts for $14.4 \%(N=15)$. Thus future multi-center studies on a larger cohort were needed to verified the findings. In addition, the present study mainly focused on the associations of disease severity and mortality with whole blood metal(loid)s, but did not excluded the effect of comorbidities, which should also be noticed in future studies.

In conclusion, we provided a comprehensive analysis of the abnormalities of 12 metal(loid)s for the COVID-19 disease. Whole blood calcium, chromium and copper were higher, while magnesium, manganese, iron, zinc, arsenic, thallium and lead were lower in the severe patients. Among the severe patients, chromium and cadmium were higher, while arsenic were lower in the deceased group. Our study determined the iron and arsenic, and age and sex were independent factors associated with the disease severity, while chromium, cadmium and the co-morbidities of cardiovascular disease were independent factors associated with the mortality. These results suggest variations of whole blood metal(loid)s as associated factors correlated with the disease progression and fatal outcome, which could be persistently monitored, and would be helpful in the evaluation of the dynamic changes in patients with COVID-19.

\section{Declarations}

\section{Ethics approval and consent to participate}

This study was approved by the Ethics Committee of Tongji Hospital, Tongji Medical College, Huazhong University of Science and Technology in Wuhan, China (No.:TJ-IRB20200201). All the procedures involving human samples conformed to the principles outlined in the Declaration of Helsinki. All the analysis were performed on existing samples collected during standard diagnostic tests, posing no extra burden to patients.

\section{Consent for publication}

Not applicable.

\section{Availability of data and materials}

The datasets used and/or analyzed during the current study are available from the corresponding author on reasonable request.

\section{Competing interests}

The authors declare that they have no competing interests.

\section{Funding}


The work was supported by National Natural Science Foundation of China (31600666).

\section{Authors' contributions}

HLZ and LC conceived the idea of the study; HLZ, QY and PY analyzed the data; HLZ, QY, XW interpreted the results; HLZ and LC wrote the paper; all authors discussed the results and revised the manuscript.

\section{Acknowledgements}

The authors thank all the medical care workers who participated in the sample collection.

\section{References}

1. Zhu N, Zhang D, Wang W, Li X, Yang B, Song J, Zhao X, Huang B, Shi W, Lu R, Niu P, Zhan F, Ma X, Wang D, Xu W, Wu G, Gao GF, Tan W, China Novel Coronavirus I, Research T (2020) A Novel Coronavirus from Patients with Pneumonia in China, 2019. The New England journal of medicine 382 (8):727-733. doi:10.1056/NEJMoa2001017

2. Guan WJ, Ni ZY, Hu Y, Liang WH, Ou CQ, He JX, Liu L, Shan H, Lei CL, Hui DSC, Du B, Li LJ, Zeng G, Yuen KY, Chen RC, Tang CL, Wang T, Chen PY, Xiang J, Li SY, Wang JL, Liang ZJ, Peng YX, Wei L, Liu Y, Hu YH, Peng P, Wang JM, Liu JY, Chen Z, Li G, Zheng ZJ, Qiu SQ, Luo J, Ye CJ, Zhu SY, Zhong NS, China Medical Treatment Expert Group for C (2020) Clinical Characteristics of Coronavirus Disease 2019 in China. The New England journal of medicine. doi:10.1056/NEJMoa2002032

3. Sarzi-Puttini P, Giorgi V, Sirotti S, Marotto D, Ardizzone S, Rizzardini G, Antinori S, Galli M (2020) COVID-19, cytokines and immunosuppression: what can we learn from severe acute respiratory syndrome? Clinical and experimental rheumatology 38 (2):337-342

4. Huang C, Wang Y, Li X, Ren L, Zhao J, Hu Y, Zhang L, Fan G, Xu J, Gu X, Cheng Z, Yu T, Xia J, Wei Y, Wu W, Xie X, Yin W, Li H, Liu M, Xiao Y, Gao H, Guo L, Xie J, Wang G, Jiang R, Gao Z, Jin Q, Wang J, Cao B (2020) Clinical features of patients infected with 2019 novel coronavirus in Wuhan, China. The Lancet 395 (10223):497-506. doi:10.1016/s0140-6736(20)30183-5

5. Sun K, Chen J, Viboud C (2020) Early epidemiological analysis of the coronavirus disease 2019 outbreak based on crowdsourced data: a population-level observational study. The Lancet Digital health 2 (4):e201-e208. doi:10.1016/s2589-7500(20)30026-1

6. Singh AK, Gillies CL, Singh R, Singh A, Chudasama Y, Coles B, Seidu S, Zaccardi F, Davies MJ, Khunti K (2020) Prevalence of co-morbidities and their association with mortality in patients with COVID-19: A systematic review and meta-analysis. Diabetes, obesity \& metabolism. doi:10.1111/dom.14124

7. Razzaque MS (2020) COVID-19 Pandemic: Can Maintaining Optimal Zinc Balance Enhance Host Resistance? The Tohoku journal of experimental medicine 251 (3):175-181. doi:10.1620/tjem.251.175

8. Iddir M, Brito A, Dingeo G, Fernandez Del Campo SS, Samouda H, La Frano MR, Bohn T (2020) Strengthening the Immune System and Reducing Inflammation and Oxidative Stress through Diet 
and Nutrition: Considerations during the COVID-19 Crisis. Nutrients 12 (6). doi:10.3390/nu12061562

9. Calder PC, Carr AC, Gombart AF, Eggersdorfer M (2020) Optimal Nutritional Status for a Well-

Functioning Immune System Is an Important Factor to Protect against Viral Infections. Nutrients 12 (4). doi:10.3390/nu12041181

10. Gombart AF, Pierre A, Maggini S (2020) A Review of Micronutrients and the Immune System-Working in Harmony to Reduce the Risk of Infection. Nutrients 12 (1). doi:10.3390/nu12010236

11. Rhee SY, Hwang YC, Woo JT, Sinn DH, Chin SO, Chon S, Kim YS (2013) Blood lead is significantly associated with metabolic syndrome in Korean adults: an analysis based on the Korea National Health and Nutrition Examination Survey (KNHANES), 2008. Cardiovascular diabetology 12:9. doi:10.1186/1475-2840-12-9

12. Moon SS (2013) Association of lead, mercury and cadmium with diabetes in the Korean population: the Korea National Health and Nutrition Examination Survey (KNHANES) 2009-2010. Diabetic medicine : a journal of the British Diabetic Association 30 (4):e143-148. doi:10.1111/dme.12103

13. Tellez-Plaza M, Guallar E, Howard BV, Umans JG, Francesconi KA, Goessler W, Silbergeld EK, Devereux RB, Navas-Acien A (2013) Cadmium exposure and incident cardiovascular disease. Epidemiology 24 (3):421-429. doi:10.1097/EDE.0b013e31828b0631

14. Tsatsakis A, Petrakis D, Nikolouzakis TK, Docea AO, Calina D, Vinceti M, Goumenou M, Kostoff RN, Mamoulakis C, Aschner M, Hernandez AF (2020) COVID-19, an opportunity to reevaluate the correlation between long-term effects of anthropogenic pollutants on viral epidemic/pandemic events and prevalence. Food and chemical toxicology : an international journal published for the British Industrial Biological Research Association 141:111418. doi:10.1016/j.fct.2020.111418

15. Xu X, Hu H, Hong YA (2017) Body burden of heavy metals among HIV high risk population in USA. Environmental pollution 220 (Pt B):1121-1126. doi:10.1016/j.envpol.2016.11.023

16. Xu X, Hu H, Dailey AB, Kearney G, Talbott EO, Cook RL (2013) Potential health impacts of heavy metals on HIV-infected population in USA. PloS one 8 (9):e74288. doi:10.1371/journal.pone.0074288

17. NHCo C (2020) Diagnosis and Treatment Scheme of New Coronavirus Infected Pneumonia.

18. Zeng HL, Li H, Lu J, Guan Q, Cheng L (2019) Assessment of 12 Metals and Metalloids in Blood of General Populations Living in Wuhan of China by ICP-MS. Biological trace element research 189 (2):344-353. doi:10.1007/s12011-018-1486-8

19. Wallace TC (2020) Combating COVID-19 and Building Immune Resilience: A Potential Role for Magnesium Nutrition? Journal of the American College of Nutrition:1-9. doi:10.1080/07315724.2020.1785971

20. Iotti S, Wolf F, Mazur A, Maier JA (2020) The COVID-19 pandemic: is there a role for magnesium? Hypotheses and perspectives. Magnesium research. doi:10.1684/mrh.2020.0465

21. Marazuela M, Giustina A, Puig-Domingo M (2020) Endocrine and metabolic aspects of the COVID-19 pandemic. Reviews in endocrine \& metabolic disorders. doi:10.1007/s11154-020-09569-2

22. Cappellini F, Brivio R, Casati M, Cavallero A, Contro E, Brambilla P (2020) Low levels of total and ionized calcium in blood of COVID-19 patients. Clinical chemistry and laboratory medicine. 
doi:10.1515/cclm-2020-0611

23. Zhou Q, Guo W, Jia Y, Xu J (2019) Comparison of Chromium and Iron Distribution in Serum and Urine among Healthy People and Prediabetes and Diabetes Patients. BioMed Research International 2019:1-8. doi:10.1155/2019/3801639

24. Lewicki S, Zdanowski R, Krzyzowska M, Lewicka A, Debski B, Niemcewicz M, Goniewicz M (2014) The role of Chromium III in the organism and its possible use in diabetes and obesity treatment. Annals of agricultural and environmental medicine : AAEM 21 (2):331-335. doi:10.5604/12321966.1108599

25. Shrivastava R, Upreti RK, Seth PK, Chaturvedi UC (2002) Effects of chromium on the immune system. FEMS immunology and medical microbiology 34 (1):1-7. doi:10.1111/j.1574-695X.2002.tb00596.x

26. Hood Ml, Skaar EP (2012) Nutritional immunity: transition metals at the pathogen-host interface. Nature reviews Microbiology 10 (8):525-537. doi:10.1038/nrmicro2836

27. Wang C, Guan Y, Lv M, Zhang R, Guo Z, Wei X, Du X, Yang J, Li T, Wan Y, Su X, Huang X, Jiang Z (2018) Manganese Increases the Sensitivity of the cGAS-STING Pathway for Double-Stranded DNA and Is Required for the Host Defense against DNA Viruses. Immunity 48 (4):675-687 e677. doi:10.1016/j.immuni.2018.03.017

28. Edeas M, Saleh J, Peyssonnaux C (2020) Iron: Innocent bystander or vicious culprit in COVID-19 pathogenesis? International journal of infectious diseases : IJID : official publication of the International Society for Infectious Diseases 97:303-305. doi:10.1016/j.ijid.2020.05.110

29. Zhao K, Huang J, Dai D, Feng Y, Liu L, Nie S (2020) Serum Iron Level as a Potential Predictor of Coronavirus Disease 2019 Severity and Mortality: A Retrospective Study. Open forum infectious diseases 7 (7):ofaa250. doi:10.1093/ofid/ofaa250

30. Bolondi G, Russo E, Gamberini E, Circelli A, Meca MCC, Brogi E, Viola L, Bissoni L, Poletti V, Agnoletti V (2020) Iron metabolism and lymphocyte characterisation during Covid-19 infection in ICU patients: an observational cohort study. World journal of emergency surgery : WJES 15 (1):41. doi:10.1186/s13017-020-00323-2

31. Rahman MT, Idid SZ (2020) Can Zn Be a Critical Element in COVID-19 Treatment? Biological trace element research. doi:10.1007/s12011-020-02194-9

32. Doboszewska U, Wlaz P, Nowak G, Mlyniec K (2020) Targeting zinc metalloenzymes in COVID-19. British journal of pharmacology. doi:10.1111/bph.15199

33. Zhou P, Yang XL, Wang XG, Hu B, Zhang L, Zhang W, Si HR, Zhu Y, Li B, Huang CL, Chen HD, Chen J, Luo Y, Guo H, Jiang RD, Liu MQ, Chen Y, Shen XR, Wang X, Zheng XS, Zhao K, Chen QJ, Deng F, Liu LL, Yan B, Zhan FX, Wang YY, Xiao GF, Shi ZL (2020) A pneumonia outbreak associated with a new coronavirus of probable bat origin. Nature 579 (7798):270-273. doi:10.1038/s41586-020-2012-7

34. Besold AN, Culbertson EM, Culotta VC (2016) The Yin and Yang of copper during infection. Journal of biological inorganic chemistry : JBIC : a publication of the Society of Biological Inorganic Chemistry 21 (2):137-144. doi:10.1007/s00775-016-1335-1 
35. Ilback NG, Frisk P, Tallkvist J, Gadhasson IL, Blomberg J, Friman G (2008) Gastrointestinal uptake of trace elements are changed during the course of a common human viral (Coxsackievirus B3) infection in mice. Journal of trace elements in medicine and biology : organ of the Society for Minerals and Trace Elements 22 (2):120-130. doi:10.1016/j.jtemb.2007.12.001

36. Cernat RI, Mihaescu T, Vornicu M, Vione D, Olariu RI, Arsene C (2011) Serum trace metal and ceruloplasmin variability in individuals treated for pulmonary tuberculosis. The international journal of tuberculosis and lung disease : the official journal of the International Union against Tuberculosis and Lung Disease 15 (9):1239-1245, i. doi:10.5588/ijtld.10.0445

37. Li CX, Gleason JE, Zhang SX, Bruno VM, Cormack BP, Culotta VC (2015) Candida albicans adapts to host copper during infection by swapping metal cofactors for superoxide dismutase. Proceedings of the National Academy of Sciences of the United States of America 112 (38):E5336-5342. doi:10.1073/pnas.1513447112

38. Malavolta M, Piacenza F, Basso A, Giacconi R, Costarelli L, Mocchegiani E (2015) Serum copper to zinc ratio: Relationship with aging and health status. Mechanisms of Ageing and Development 151:93-100. doi:10.1016/j.mad.2015.01.004

39. Rehman K, Fatima F, Waheed I, Akash MSH (2018) Prevalence of exposure of heavy metals and their impact on health consequences. Journal of cellular biochemistry 119 (1):157-184. doi:10.1002/jcb.26234

40. Bortey-Sam N, Ikenaka Y, Akoto O, Nakayama SMM, Asante KA, Baidoo E, Obirikorang C, Mizukawa H, Ishizuka M (2018) Association between human exposure to heavy metals/metalloid and occurrences of respiratory diseases, lipid peroxidation and DNA damage in Kumasi, Ghana. Environmental pollution 235:163-170. doi:10.1016/j.envpol.2017.12.005

41. Sun S, Cai X, Wang H, He G, Lin Y, Lu B, Chen C, Pan Y, Hu X (2020) Abnormalities of peripheral blood system in patients with COVID-19 in Wenzhou, China. Clinica chimica acta; international journal of clinical chemistry 507:174-180. doi:10.1016/j.cca.2020.04.024

\section{Tables}


Table 1. Basic characteristics of the patients with

COVID-19.

\begin{tabular}{|c|c|c|c|c|}
\hline & All patients $(\mathrm{N}=306)$ & $\begin{array}{l}\text { Non-severe }(\mathrm{N}= \\
202)\end{array}$ & $\begin{array}{l}\text { Severe }(\mathrm{N}= \\
104)\end{array}$ & \\
\hline Age, median (IQR), y & $63.0(53.3-70.0)$ & $69.0(62.0-78.0))$ & $\begin{array}{l}58.0(50.3- \\
66.0))\end{array}$ & $\dot{0} 001$ \\
\hline Sex & & & & 0.019 \\
\hline Male & $148(48.4 \%)$ & $60(57.7 \%)$ & $88(43.6 \%)$ & \\
\hline Female & $158(51.6 \%)$ & $44(42.3 \%)$ & $114(56.4 \%)$ & \\
\hline Outcome & & & & 0.001 \\
\hline Recovered & $291(95.1 \%)$ & $89(85.6 \%)$ & $202(100 \%)$ & \\
\hline Deceased & $15(4.9 \%)$ & $15(14.4 \%)$ & $0(0 \%)$ & \\
\hline Length of stay (IQR), d & $30(19-41)$ & $22(17-33)$ & $41(35-46)$ & $\dot{0} 001$ \\
\hline Onset to admission (IQR), d & $21(11-34)$ & $27(12-38)$ & $15(9-21)$ & ¿. 001 \\
\hline \multicolumn{5}{|l|}{ Initial symptoms } \\
\hline Fever & $202(66.0 \%)$ & $125(61.9 \%)$ & $76(73.1 \%)$ & 0.051 \\
\hline Cough & $207(67.6 \%)$ & $131(64.9 \%)$ & $75(72.1 \%)$ & 0.199 \\
\hline Feebleness & $85(27.8 \%)$ & $54(26.7 \%)$ & $30(28.8 \%)$ & 0.695 \\
\hline Chest tightness & $110(35.9 \%)$ & $68(33.7 \%)$ & $41(39.4 \%)$ & 0.319 \\
\hline Shortness of breath & $72(23.5 \%)$ & $37(18.3 \%)$ & $35(33.7 \%)$ & 0.003 \\
\hline Diarrhea & $38(12.4 \%)$ & $29(14.4 \%)$ & $8(7.7 \%)$ & 0.090 \\
\hline \multicolumn{5}{|l|}{ Comorbidities } \\
\hline Hypertension & $118(38.6 \%)$ & $67(33.2 \%)$ & $51(49.0 \%)$ & 0.007 \\
\hline Cardiovascular disease & $42(13.7 \%)$ & $22(10.9 \%)$ & $20(19.2 \%)$ & 0.045 \\
\hline Diabetes & $59(19.3 \%)$ & $31(15.3 \%)$ & $28(26.9 \%)$ & 0.015 \\
\hline Malignancy & $14(4.6 \%)$ & $8(4.0 \%)$ & $6(5.8 \%)$ & 0.473 \\
\hline Cerebrovascular disease & $19(6.2 \%)$ & $10(5.0 \%)$ & $9(8.7 \%)$ & 0.204 \\
\hline None & $68(22.2 \%)$ & $47(23.3 \%)$ & $21(10.4 \%)$ & 0.540 \\
\hline
\end{tabular}


Table 2. levels of whole blood metal(loid)s in non-severe and severe patients with COVID-19.

\begin{tabular}{|c|c|c|c|c|}
\hline \multirow{2}{*}{$\begin{array}{l}\text { Elements (reference } \\
\text { range), IQR }\end{array}$} & \multicolumn{4}{|c|}{ Disease status, median (IQR) } \\
\hline & All & Non-severe & Severe & $p$ \\
\hline $\mathrm{Mg}(31.9-48.0), \mathrm{mg} / \mathrm{L}$ & $\begin{array}{l}39.13(36.63- \\
41.94)\end{array}$ & $\begin{array}{l}39.46(37.07- \\
42.31)\end{array}$ & $38.33(35.18-40.4)$ & 0.002 \\
\hline $\mathrm{Ca}(46.9-66.8), \mathrm{mg} / \mathrm{L}$ & $\begin{array}{l}64.54(60.61- \\
69.12)\end{array}$ & $\begin{array}{l}63.55(60.02- \\
67.47)\end{array}$ & $\begin{array}{l}68.20(61.85- \\
71.93)\end{array}$ & $<.001$ \\
\hline $\mathrm{Cr}(<0.50-0.76), \mathrm{mg} / \mathrm{L}$ & $0.85(0.72-1.08)$ & $0.81(0.69-0.97)$ & $1.03(0.8-1.3)$ & $<.001$ \\
\hline $\mathrm{Mn}(8.1-18.5), \mathrm{mg} / \mathrm{L}$ & $\begin{array}{l}12.05(9.74 \text { - } \\
14.77)\end{array}$ & $\begin{array}{l}12.96(10.63- \\
15.43)\end{array}$ & $10.56(8.63-13.13)$ & $\hat{0.001}$ \\
\hline $\mathrm{Fe}(406.5$ - 576.7), mg/L & $\begin{array}{l}419.87(363.42 \text { - } \\
465.34)\end{array}$ & $\begin{array}{l}436.8(393.26- \\
479.73)\end{array}$ & $\begin{array}{l}370.24(330.04- \\
428.21)\end{array}$ & $<.001$ \\
\hline $\mathrm{Cu}(634.1$ - 999.4), mg/L & $\begin{array}{l}865.02(779.75 \text { - } \\
987.13)\end{array}$ & $\begin{array}{l}838.55(770.47- \\
950.13)\end{array}$ & $\begin{array}{l}929.73(828.52- \\
1080.02)\end{array}$ & $\hat{0} .001$ \\
\hline $\mathrm{Zn}(4.3-7.8), \mathrm{mg} / \mathrm{L}$ & $6.44(5.84-7.09)$ & $6.61(5.91-7.25)$ & $6.18(5.67-6.79)$ & 0.001 \\
\hline As $(0.93-8.14), \mathrm{mg} / \mathrm{L}$ & $1.43(1.05-1.84)$ & $1.59(1.25-1.99)$ & $1.09(0.77-1.45)$ & $<.001$ \\
\hline $\mathrm{Cd}(0.22-6.44), \mathrm{mg} / \mathrm{L}$ & $0.70(0.49-0.99)$ & $0.71(0.48-1.01)$ & $0.7(0.5-0.96)$ & 0.654 \\
\hline $\mathrm{Hg}(<1.15-5.97), \mathrm{mg} / \mathrm{L}$ & $1.56(1.15-2.11)$ & $1.68(1.2-2.1)$ & $1.45(<1.15-2.12)$ & 0.119 \\
\hline $\mathrm{TI}(<0.05-0.09), \mathrm{mg} / \mathrm{L}$ & $\begin{array}{l}<0.05(<0.05- \\
0.06)\end{array}$ & $0.05(<0.05-0.06)$ & $\begin{array}{l}<0.05(<0.05- \\
0.05)\end{array}$ & $\hat{0.001}$ \\
\hline $\mathrm{Pb}(8.7-48.1), \mathrm{mg} / \mathrm{L}$ & $\begin{array}{l}11.56(9.06- \\
15.73)\end{array}$ & $\begin{array}{l}12.37(9.51 \text { - } \\
16.32)\end{array}$ & $10.57(8.78-14.51)$ & 0.012 \\
\hline
\end{tabular}

Abbreviations: $\mathrm{Mg}$, magnesium; $\mathrm{Ca}$, calcium; $\mathrm{Cr}$, chromium; $\mathrm{Mn}$, manganese; $\mathrm{Fe}$, iron; $\mathrm{Cu}$, copper; $\mathrm{Zn}$, Zinc; As, arsenic; Cd, cadmium; $\mathrm{Hg}$, mercury; $\mathrm{Tl}$, thallium; Pb, lead. 
Table 3. levels of whole blood metal(loid)s in recovered and deceased patients with severe COVID-19.

\section{Elements}

\begin{tabular}{|c|c|c|c|}
\hline & & & \\
\hline & Recovered & Deceased & $p$ \\
\hline Age, median (IQR), y & $69(62-77.5)$ & $69(67-81)$ & 0.311 \\
\hline Sex & & & 0.185 \\
\hline Male & $49(55.1 \%)$ & $11(73.3 \%)$ & \\
\hline Female & $40(44.9 \%)$ & $4(26.7 \%)$ & \\
\hline \multicolumn{4}{|c|}{$\begin{array}{l}\text { Whole blood elements (reference } \\
\text { range), IQR }\end{array}$} \\
\hline $\mathrm{Mg}(31.9-48.0), \mathrm{mg} / \mathrm{L}$ & $38.29(35-40.49)$ & $38.39(36.18-40.19)$ & 0.681 \\
\hline $\mathrm{Ca}(46.9-66.8), \mathrm{mg} / \mathrm{L}$ & $68.72(62.39$ - 71.92) & $64.53(60.51-72.57)$ & 0.491 \\
\hline $\mathrm{Cr}(<0.50-0.76), \mathrm{mg} / \mathrm{L}$ & $0.96(0.78-1.19)$ & $1.5(1.05-1.87)$ & 0.001 \\
\hline $\mathrm{Mn}(8.1$ - 18.5), mg/L & $10.63(8.74-13.25)$ & $10.38(8.13-13.01)$ & 0.687 \\
\hline $\mathrm{Fe}(406.5$ - 576.7), mg/L & $\begin{array}{l}371.33(331.57- \\
430.26)\end{array}$ & $\begin{array}{l}342.58(316.07- \\
413.32)\end{array}$ & 0.424 \\
\hline $\mathrm{Cu}(634.1$ - 999.4), mg/L & $\begin{array}{l}925.22(828.7- \\
1076.39)\end{array}$ & $\begin{array}{l}999.29(820.21- \\
1114.67)\end{array}$ & 0.392 \\
\hline $\mathrm{Zn}(4.3-7.8), \mathrm{mg} / \mathrm{L}$ & $6.15(5.65$ - 6.79) & $6.22(5.81$ - 6.99) & 0.508 \\
\hline As $(0.93-8.14), \mathrm{mg} / \mathrm{L}$ & $1.14(0.84-1.52)$ & $0.85(0.52-0.96)$ & 0.002 \\
\hline $\mathrm{Cd}(0.22-6.44), \mathrm{mg} / \mathrm{L}$ & $0.63(0.45-0.9)$ & $0.8(0.77-1.78)$ & 0.002 \\
\hline $\mathrm{Hg}(<1.15-5.97), \mathrm{mg} / \mathrm{L}$ & $1.45(<1.15-2)$ & $1.82(<1.15-3.29)$ & 0.187 \\
\hline $\mathrm{TI}(<0.05-0.09), \mathrm{mg} / \mathrm{L}$ & $<0.05(<0.05-0.05)$ & $<0.05(<0.05-<0.05)$ & 0.622 \\
\hline $\mathrm{Pb}(8.7-48.1), \mathrm{mg} / \mathrm{L}$ & $10.55(8.92-14.31)$ & $10.64(6.42-16.9)$ & 0.647 \\
\hline
\end{tabular}

Abbreviations: $\mathrm{Mg}$, magnesium; $\mathrm{Ca}$, calcium; $\mathrm{Cr}$, chromium; Mn, manganese; $\mathrm{Fe}$, iron; $\mathrm{Cu}$, copper; $\mathrm{Zn}$, Zinc; As, arsenic; Cd, cadmium; $\mathrm{Hg}$, mercury; $\mathrm{Tl}$, thallium; $\mathrm{Pb}$, lead. 
Table 4. The risk factors for severe illness in COVID-19 patients by using cut-off points.

\begin{tabular}{|c|c|c|c|c|}
\hline \multirow[t]{2}{*}{ Parameter } & \multirow[t]{2}{*}{ Non-severe } & \multirow[t]{2}{*}{ Severe } & \multicolumn{2}{|l|}{ Multivariate } \\
\hline & & & OR $(95 \% \mathrm{Cl})$ & $p$ \\
\hline \multicolumn{5}{|l|}{ Age, years } \\
\hline$\geq 65$ & 61 & 73 & $3.667(2.069-6.5)$ & $<0.001$ \\
\hline$<65$ & 141 & 31 & & \\
\hline \multicolumn{5}{|l|}{ Sex } \\
\hline Male & 88 & 60 & $1.962(1.123-3.43)$ & 0.018 \\
\hline Female & 114 & 44 & & \\
\hline \multicolumn{5}{|l|}{$\mathrm{Fe}, \mathrm{mg} / \mathrm{L}$} \\
\hline$\nabla 376.67$ & 39 & 57 & $2.406(4.427-1.308)$ & 0.005 \\
\hline$\geq 376.67$ & 163 & 47 & & \\
\hline \multicolumn{5}{|l|}{ As, $\mathrm{mg} / \mathrm{L}$} \\
\hline$\nabla 1.24$ & 48 & 65 & $3.136(5.622-1.749)$ & $<0.001$ \\
\hline$\geq 1.24$ & 154 & 39 & & \\
\hline
\end{tabular}

Abbreviations: Fe, iron; As, arsenic. 
Table 5. The risk factors for fatal outcome in COVID-19 patients by using cut-off points.

\begin{tabular}{|c|c|c|c|c|}
\hline \multirow[t]{2}{*}{ Parameter } & \multirow[t]{2}{*}{ Recovered } & \multirow[t]{2}{*}{ Deceased } & \multicolumn{2}{|l|}{ Multivariate } \\
\hline & & & OR (95\% Cl) & $p$ \\
\hline \multicolumn{5}{|l|}{$\mathrm{Cr}, \mathrm{mg} / \mathrm{L}$} \\
\hline$\geq 1.32$ & 15 & 10 & $9.595(2.143-42.956)$ & 0.0031 \\
\hline$\nabla 1.32$ & 74 & 5 & & \\
\hline \multicolumn{5}{|l|}{$\mathrm{Cd}, \mathrm{mg} / \mathrm{L}$} \\
\hline$\geq 0.68$ & 40 & 14 & $12.734(1.363-119.006)$ & 0.026 \\
\hline$\nabla 0.68$ & 49 & 1 & & \\
\hline \multicolumn{5}{|c|}{ Cardiovascular diseases } \\
\hline Y & 15 & 5 & $6.91(1.29-37.005)$ & 0.024 \\
\hline$N$ & 74 & 10 & & \\
\hline
\end{tabular}

Abbreviations: $\mathrm{Cr}$, chromium; $\mathrm{Cd}$, cadmium.

Figures 


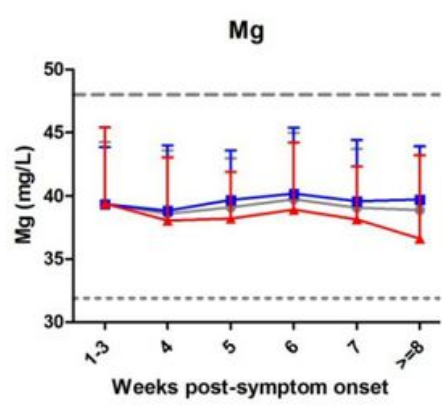

$\mathrm{Fe}$

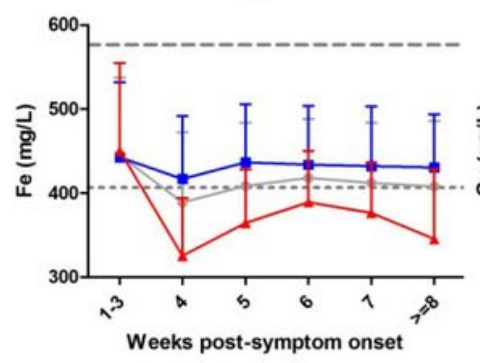

Cd

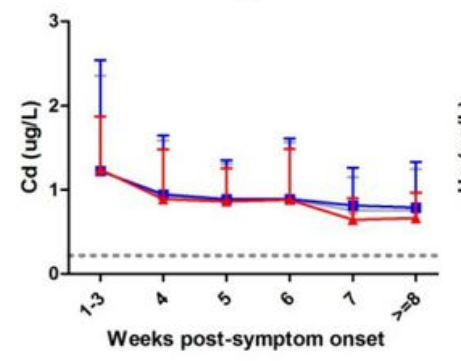

Ca

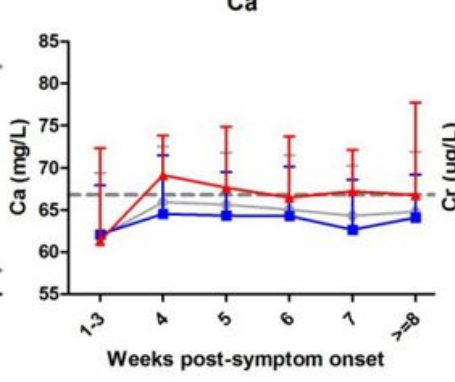

$\mathrm{Cu}$

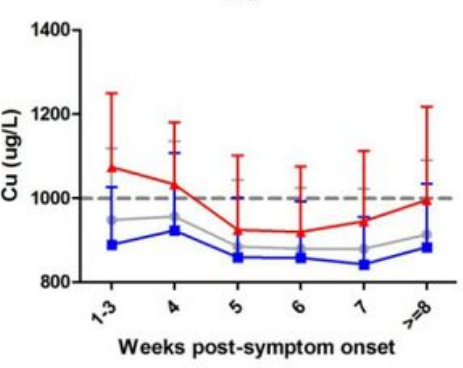

cr

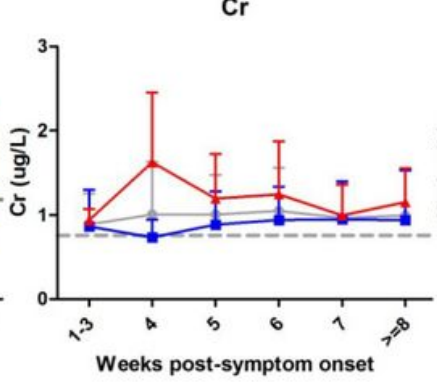

Zn

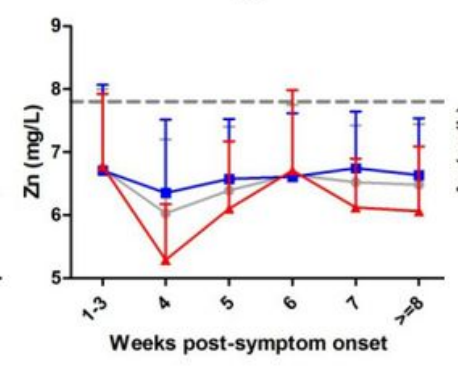

TI

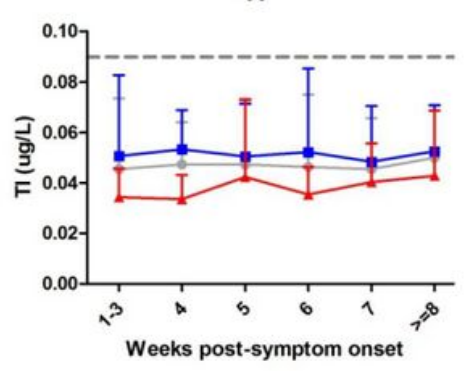

Mn

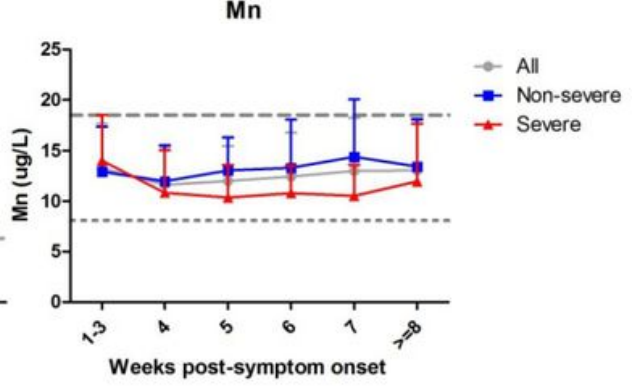

As

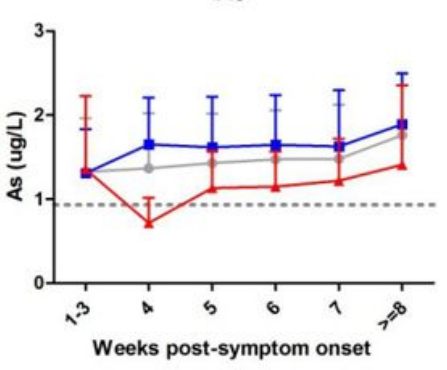

$\mathrm{Pb}$

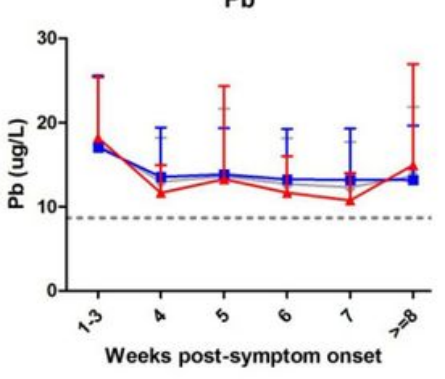

Figure 1

Longitudinal dynamic profiles of the 12 metal(loid)s in whole blood of 306 COVID-19 patients according to the disease severity (non-severe, severe and total cases). The mean values were delineated on weeks of disease onset. Data are shown as mean \pm SD. Abbreviations: Mg, magnesium; Ca, calcium; Cr, chromium; Mn, manganese; Fe, iron; Cu, copper; Zn, zinc; As, arsenic; Cd, cadmium; Hg, mercury; Tl, thallium; Pb, lead.

\section{Supplementary Files}

This is a list of supplementary files associated with this preprint. Click to download.

- SupplementaryMaterials.docx 